\title{
Using lead isotope ratios to distinguish between samples of diffrent uranium mines
}

\author{
Tebogo Gilbert Kupi ${ }^{1,2}$ (1) $\cdot$ Vera Uushona ${ }^{1} \cdot$ Manny Mathuthu $^{1} \cdot$ Marthie Coetzee ${ }^{2} \cdot$ Danel van Tonder $^{2}$
}

Received: 1 July 2019 / Published online: 12 February 2020

(c) The Author(s) 2020

\begin{abstract}
In this work, a total of twenty samples selected for investigation originate from South Africa and Namibia uranium mines. The aim of this study was to determine whether the lead ratios measured in particular samples could be used to attribute the uranium sample to the production or reprocessing plant. Measurements were carried out using an inductively coupled plasma mass spectrometer PerkinElmer NexION 2000. The precision obtained for the ${ }^{208} \mathrm{~Pb} /{ }^{206} \mathrm{~Pb}$ ratio, the ${ }^{207} \mathrm{~Pb} /{ }^{206} \mathrm{~Pb}$ ratio and the ${ }^{204} \mathrm{~Pb} /{ }^{206} \mathrm{~Pb}$ ratio values was considerably lower than $0.02 \%$ demonstrating the applicability of the technique for $\mathrm{Pb}$ isotope ratio studies.
\end{abstract}

Keywords Lead isotopic ratio $\cdot$ Nuclear forensic signatures $\cdot$ ICP-MS

\section{Introduction}

Illicit trafficking of radioactive material and especially nuclear material (thorium, uranium, and plutonium) has been an issue of concern since the beginning of the 1990s, when the first seizures of nuclear material were reported to the International Atomic Energy Agency [1]. However throughout the world, nuclear and radioactive materials are used daily for beneficial purposes, in industry, medicine, agriculture and research. The use of nuclear and radioactive material generates some risk due to radiation being emitted, which is harmful to human health especially if they enter the human body even at low levels (i.e. microgram amounts)

Tebogo Gilbert Kupi

Tebogo.Kupi@nwu.ac.za

Vera Uushona

nvuushona@yahoo.com

Manny Mathuthu

Manny.Mathuthu@nwu.ac.za

Marthie Coetzee

Marthie.Coetzee@nwu.ac.za

Danel van Tonder

Danel.VanTonder@nwu.ac.za

1 North-West University, Mafikeng Campus: Corner of Albert Luthuli and University Drive, Mmabatho 2745, South Africa

2 North-West University, Potchefstroom Campus, 11 Hoffman Street, Potchefstroom 2531, South Africa
[2]. The main security concerns relating to their use, are perceived ease of access to them, the culture of personnel responsible for managing the material, and the potential for theft and construction of radiological dispersive devices (RDDs) also referred to as "dirty" bombs [3, 4].

The clear evidence of significant amount of nuclear material outside regulatory control has created international concern over the importance of maintaining global nuclear order [4]. This has resulted in the development of a new branch of science called "Nuclear Forensics" with the intent not only to identify and characterize illicit nuclear or radioactive material but also to learn more about the intended use of the seized material as well as its origin and about the potential trafficking route. [4, 5].

Applying Nuclear Forensics as a fingerprinting tool to compare with reference data allows the researcher to determine the origin, the intended use, the last legal owner and the smuggling route of the nuclear or radioactive material [6]. This makes Nuclear Forensics to be a key element of Nuclear Security.

In South Africa, the Nuclear Forensics efforts are still in a developing stage. In nuclear forensics, the isotopic composition of nuclear material aid as one of the parameters that contribute to "nuclear fingerprint" of the material and thereby provide a basis for drawing conclusions on the potential origin of the material. Nuclear fingerprinting refers to the determination of origin, mode of production from the composition of nuclear material [5]. In the context of this 
work, fingerprinting would refer to the process of identifying signatures in the nuclear fuel cycle.

Signatures are measurable attributes of nuclear fuel cycles [7]. Therefore nuclear forensic analysis is a key technical capability that utilizes signatures inherent to nuclear or other radioactive material to provide information on its source, production and history $[8,9]$. This study investigates the application of lead isotopic ratios and lanthanides pattern in nuclear forensics.

\section{Lead isotopic composition}

In South Africa, the uranium is produced as a by-product of gold or copper mining $[10,11]$ while in Namibia uranium is directly mined from the uranium mine. The proportion of the lead isotopes is constant in nature regardless of the type of mineral or deposit in which the uranium is found [12]. Another parameter of main interest in uranium/gold mining, is the level of trace elements or impurities [13]. These trace elements are of great interest to nuclear forensics, because they can be used to attribute the uranium material to its geological source, i.e., to a uranium ore deposit type [14].

Measuring the stable isotope such as Lead $(\mathrm{Pb})$ is an established technique in geolocation $[6,15]$. Natural $\mathrm{Pb}$ is composed of four stable isotopes, and the International Union of Pure and Applied Chemistry (IUPAC) [16] reports small natural variations on the representative isotopic composition: ${ }^{204} \mathrm{~Pb}-1.4 \%,{ }^{206} \mathrm{~Pb}-24.1 \%,{ }^{207} \mathrm{~Pb}-22.1 \%$ and ${ }^{208} \mathrm{~Pb}-52.4 \%$. Therefore the stable lead isotope composition gives information on the initial U/Th ratio in the ore deposits and on the age of the ore. Due to the fact that the variations in the composition for different mines are significant, investigating the stable lead isotopes can locate the original mine.

\section{Methodology}

Measurement of nuclear material is the backbone of the verification measurements in the nuclear forensics environment and thus provide clue for determination of sample origin. Measurements of nuclear material can provide information on the uranium content, as well as uranium isotopic composition in a given material. However, the measurements methods of nuclear material is an elaborate and time-consuming process. The measurements requires clean working environment to monitor the impurity levels that arise from any working procedure involved.

\section{Samples}

Samples selected for this study are water samples recovered from the mine tailings for reuse in the plant samples collected from the uranium mines areas. The water samples in this case was part of the reprocessing from the mine waste which is an intermediate step of the front end in nuclear fuel cycle. The origin for all samples used in this work cannot be revealed due to confidentiality agreements with the mines.

\section{Samples preparation}

A total of 20 water samples from two mines area were collected and used for analysis with inductively coupled plasma mass spectrometer (ICP-MS). A set of ten samples were collected from South African uranium mine area and another ten set of samples from Namibian mine area. A water sample of $5 \mathrm{~mL}$ each were mixed with $1 \mathrm{~mL}$ of $70 \%$ high purity nitric acid $\left(\mathrm{HNO}_{3}\right)$ (Sigma Aldrich, South Africa). All solutions were prepared with $18 \mathrm{M} \Omega$ Millipore Milli-Q system distilled water (Millipore, USA). For analysis of $\mathrm{Pb}$ isotope ratio, about $0.8 \mathrm{~g}$ of high-purity $\mathrm{Pb}$ metal (NIST SRM 981 standard) purchased from the National Institute of Standards and Technology (NIST) was used as a $\mathrm{Pb}$ isotope ratio standard. The $\mathrm{Pb}$ standard were dissolved in $1 \mathrm{M} \mathrm{HNO}_{3}$ to prepare a stock solution.

During the analysis, quality control samples such as blanks and certified reference materials were included in the analyses. The ICP-MS were set to run a blank and a standard check at every ten samples for every set of measurement.

\section{Instrumentation}

All analyses were conducted at North-West University's Centre for Applied Radiation Science and Technology. The instrument used in this study is a NexION 2000 ICP-MS (PerkinElmer Inc., Connecticut, USA) which is equipped with a Quadrupole ion deflector that focuses the ion beam to the dual mode detector. In addition to being highly sensitive, the NexION 2000 ICP-MS uses a helium gas collision system that greatly reduces the spectral interference caused by argon and chlorine. The instrument were optimized using the automated SmartTune ${ }^{\mathrm{TM}}$ procedure. All the data acquired were processed using the Syngistix ${ }^{\mathrm{TM}}$ Nano Application Software Module (PerkinElmer Inc.). The instrumental operating conditions and signal measurement settings are summarized in Table 1.

\section{Results}

A major advantage of the ICP-MS is sensitivity and before the start of the analysis the instrument were allowed to run for 30 min following plasma ignition to reach thermal stability. For lead isotopic ratio measurement, a $20 \mathrm{ppb}$ solution of NIST SRM 981 isotope ratio standard were measured for 5 replicates. The Pb NIST SRM 981 was used to 
Table 1 Nexion 2000 ICP-MS instrumental operating conditions

\begin{tabular}{ll}
\hline RF frequencies & $27.12 \mathrm{MHz}$ \\
RF power & $1.2 \mathrm{~kW}$ forward, <10 W reflection \\
Outer & Argon plasma flow \\
Intermediate & Nebulizer flow \\
Central & AUX flow \\
Nebulizer & Meinhard type C \\
Spray chamber & Dual sychronic/double Scott glass \\
& chamber (ambient temperature) \\
Sample uptake & $50 \mu \mathrm{L} /$ min (free aspiration) \\
Number of sweeps & 1000 \\
Number of replicates & 5 \\
Ion energy & $10,000 \mathrm{~V}$ \\
Extraction & $2000 \mathrm{~V}$ \\
Typical transmission $\mathrm{Pb}$ & $90,000 \mathrm{counts}(\mathrm{cps} / \mathrm{ppb})$ \\
\hline
\end{tabular}

$\mathrm{MHz}$, Megahertz; W, watts; $\mu \mathrm{L} / \mathrm{min}$, microliters per minute; $\mathrm{V}$, volt; cps, counts per second; ppb, parts per billion

correct the mass bias of the ICP-MS instrument used for the isotope ratio analysis. The instruments showed excellent precision as provided in Tables 2 and 3. The typical within-run precision of the isotope ratio measurement of NIST SRM 981 was less than $0.02 \%$ for ratio ${ }^{204} \mathrm{~Pb}^{1206} \mathrm{~Pb}$, ${ }^{207} \mathrm{~Pb} /{ }^{206} \mathrm{~Pb}$ and ${ }^{208} \mathrm{~Pb} /{ }^{206} \mathrm{~Pb}$. All of the laboratory utensils used in the preparation of standard and digestion were properly washed, acid-soaked and finally rinsed with $18 \mathrm{M} \Omega$ Millipore Milli-Q system distilled water prior to use.

\section{Discussion and conclusion}

The aim of this study was to determine whether the lead ratios measured in particular samples could be used to attribute the uranium sample to the production or reprocessing plant. As a means of looking for variations or similarities in the measurements of South African and Namibia water samples recovered from the mine tailings for reuse in the plant, the ratios ${ }^{204} \mathrm{~Pb} /{ }^{206} \mathrm{~Pb},{ }^{207} \mathrm{~Pb} /{ }^{206} \mathrm{~Pb}$ and ${ }^{208} \mathrm{~Pb} /{ }^{206} \mathrm{~Pb}$ were determined. In both Tables 2 and 3 the measured NIST SRM 981 and certified NIST SRM 981 [17] results are different as a results of the mass bias effect. The mass bias effect is used as a correction factor for mass bias correction. Tables 2 and 3 illustrates the data from the analyses of both South African and Namibia mine taillings and shows very interesting results. For example, the isotopic ratios ${ }^{204} \mathrm{~Pb} /{ }^{206} \mathrm{~Pb}$, ${ }^{207} \mathrm{~Pb} /{ }^{206} \mathrm{~Pb}$ and ${ }^{208} \mathrm{~Pb} /{ }^{206} \mathrm{~Pb}$ measurements results for South African mine are 1\% less than the measured NIST SRM 981 isotope ratio standard while the Namibia mine results are $1 \%$ more than the measured NIST SRM 981 isotope ratio standard.

These results confirm that, lead isotopic ratio used for origin location do reflect significant variation within mine and thus provide valuable information about the geochemical formation and origin. The difference of both results is distinct and shows that it is possible to distinguish between South Africa and Namibia uranium samples from different sources.

The South African results are similar to those obtained by Khumalo and Mathuthu [18]. These results support and strengthen national nuclear security in deterring theft of nuclear material by nuclear terrorist for non-peaceful purposes within the country, as South Africa seek to develop and establish a national nuclear forensic library.

It is recommended that comprehensive sampling be undertaken to give the full view of the forensics signatures in different stage of the nuclear fuel cycle (cradle to grave and mining to waste characterization). However, this study has clearly demonstrated that the nuclear forensics signatures from the gold/uranium mine can be distinguished
Table 2 Results of $\mathrm{Pb}$ isotope ratio measurements of South African mine tailing samples

\begin{tabular}{llll}
\hline Sample ID & ${ }^{204} \mathrm{~Pb} /{ }^{206} \mathrm{~Pb}$ & ${ }^{207} \mathrm{~Pb} /{ }^{206} \mathrm{~Pb}$ & ${ }^{208} \mathrm{~Pb} /{ }^{206} \mathrm{~Pb}$ \\
\hline $\mathrm{C} 5 \mathrm{~W}-1$ & 0.0482 & 0.8159 & 2.0108 \\
$\mathrm{C} 5 \mathrm{~W}-2$ & 0.0484 & 0.8115 & 1.9457 \\
$\mathrm{C} 5 \mathrm{~W}-3$ & 0.0498 & 0.8221 & 2.0326 \\
$\mathrm{C} 5 \mathrm{~W}-4$ & 0.0507 & 0.8269 & 2.0349 \\
$\mathrm{C} 5 \mathrm{~W}-5$ & 0.0488 & 0.8144 & 2.0434 \\
$\mathrm{C} 5 \mathrm{~W}-6$ & 0.0488 & 0.8221 & 2.0217 \\
$\mathrm{C} 5 \mathrm{~W}-7$ & 0.0496 & 0.8193 & 1.9589 \\
$\mathrm{C} 5 \mathrm{~W}-8$ & 0.0495 & 0.8192 & 2.0331 \\
$\mathrm{C} 5 \mathrm{~W}-9$ & 0.0510 & 0.8304 & 2.0427 \\
C5W-10 & 0.0487 & 0.8187 & 2.0481 \\
Mean & $0.04935 \pm 0.0017$ & $0.82005 \pm 0.0194$ & $2.01719 \pm 0.0606$ \\
Measured NIST SRM & $0.05888 \pm 0.0001$ & $0.91441 \pm 0.0036$ & $2.17061 \pm 0.0013$ \\
981 (this work) & & & \\
Certified NIST SRM & $0.059042 \pm 0.000037$ & $0.91464 \pm 0.00033$ & $2.1681 \pm 0.0008$ \\
981 [17] & & & \\
\hline
\end{tabular}


Table 3 Results of $\mathrm{Pb}$ isotope ratio measurements of Namibia mine tailing samples

\begin{tabular}{llll}
\hline Sample ID & ${ }^{204} \mathrm{~Pb} /{ }^{206} \mathrm{~Pb}$ & ${ }^{207} \mathrm{~Pb} /{ }^{206} \mathrm{~Pb}$ & ${ }^{208} \mathrm{~Pb} /{ }^{206} \mathrm{~Pb}$ \\
\hline TSF2-1 & 0.0589 & 0.9672 & 2.3113 \\
TSF2-2 & 0.0612 & 1.0153 & 2.4330 \\
TSF2-3 & 0.0584 & 0.9658 & 2.3160 \\
TSF2-4 & 0.0614 & 1.0148 & 2.4278 \\
TSF2-5 & 0.0610 & 1.0111 & 2.4209 \\
TSF2-6 & 0.0606 & 0.9993 & 2.4004 \\
TSF2-7 & 0.0605 & 1.0059 & 2.4007 \\
TSF2-8 & 0.0605 & 1.0045 & 2.4075 \\
TSF2-9 & 0.0606 & 1.0065 & 2.4037 \\
TSF2-10 & 0.0606 & 1.0020 & 2.3969 \\
Mean & $0.0604 \pm 0.00091$ & $0.9992 \pm 0.01708$ & $2.3918 \pm 0.04078$ \\
Measured NIST SRM & $0.05888 \pm 0.0001$ & $0.91441 \pm 0.0036$ & $2.17061 \pm 0.0013$ \\
981 (this work) & & & \\
Certified NIST SRM & $0.059042 \pm 0.000037$ & $0.91464 \pm 0.00033$ & $2.1681 \pm 0.0008$ \\
981 [17] & & & \\
\hline
\end{tabular}

using isotopic profiles and the ICP-MS PerkinElmer NexION 2000 is a good choice for isotope ratio analysis since it has very good nebulization efficiency and stability. Further improvements in precision of results may be carried out by slightly modifying the method used in this study. For example, Tl may be added to the sample as an internal standard [19].

Acknowledgements Authors would like to acknowledge the International Atomic Energy Agency (IAEA) for sponsoring this Project under CRP J02013, (IAEA Research Contract No: 23100/R0). Appreciation also goes to the North-West University's Centre for Applied Radiation Science and Technology (CARST) for financial support to attend and present some part of this work at the RANC2019 Conference held in Budapest, Hungary 05th-10th May 2019. Finally, we acknowledge the National Research Fund (NRF) for funding the purchase of newly installed NexION 2000 ICP-MS (PerkinElmer Inc., Connecticut, USA) at North-West University's Centre for Applied Radiation Science and Technology. Opinions expressed and conclusions arrived at, are those of the author and are not necessarily to be attributed to the NRF.

Open Access This article is licensed under a Creative Commons Attribution 4.0 International License, which permits use, sharing, adaptation, distribution and reproduction in any medium or format, as long as you give appropriate credit to the original author(s) and the source, provide a link to the Creative Commons licence, and indicate if changes were made. The images or other third party material in this article are included in the article's Creative Commons licence, unless indicated otherwise in a credit line to the material. If material is not included in the article's Creative Commons licence and your intended use is not permitted by statutory regulation or exceeds the permitted use, you will need to obtain permission directly from the copyright holder. To view a copy of this licence, visit http://creativecommons.org/licenses/by/4.0/.

\section{References}

1. Iaea I (2015) Incident and trafficking database (ITDB). Austria, Vienna, p 438
2. Aggarwal SK (2016) Nuclear forensics: what, why and how. Curr Sci 110(5):782-791

3. IAEA (2007) Combating illicit trafficking in nuclear and other radioactive material. International Atomic Energy Agency (IAEA), Vienna

4. Hutcheon ID, Kristo MJ, Knight KB (2013) Nonproliferation nuclear forensics. Uranium: cradle to Grave. Mineralogical Association of Canada, Quebec City, pp 377-394

5. Jariwala KN (2014) Nuclear forensics—a review. Int J Interdiscip Multidiscip Stud 1:152-156

6. Mathuthu M, Khumalo N (2018) Determination of lead isotope ratios in uranium mine products in South Africa by means of inductively coupled plasma mass spectrometry. J Radioanal Nucl Chem 315(1):1-12

7. Borg L, Hutcheon I, Analysis Forensic (2013) Forensic analysis of samples from the nuclear fuel cycle. Lawrence Livermore National Laboratory (LLNL), Livermore

8. Stork CL et al (2017) Dynamic analysis environment for nuclear forensic analyses. Comput Phys Commun 210:60-71

9. Kristo MJ et al (2016) Nuclear forensic science: analysis of nuclear material out of regulatory control. Annu Rev Earth Planet Sci 44:555-579

10. Mogafe PR et al (2015) South Africa's nuclear forensics response plan step 1-in support of nuclear security investigations. J Phys Sci Appl 5(3):183-190

11. Nea I (2006) Forty years of uranium resources, production and demand in perspective. The red book retrospective. OECD Publishing, Paris

12. Dahlkamp FJ (2013) Uranium ore deposits. Springer, Berlin

13. Švedkauskaitè-Le Gore J (2008) Development and validation of a method for origin determination of uranium-bearing material

14. Keegan E et al (2012) Attribution of uranium ore concentrates using elemental and anionic data. Appl Geochem 27(8):1600-1609

15. Apostol A et al (2016) Isotopic composition analysis and age dating of uranium samples by high resolution gamma ray spectrometry. Nucl Instrum Methods Phys Res Sect B Beam Interact Mater At 383:103-108

16. Margui E et al (2007) Precise and accurate determination of lead isotope ratios in mining wastes by ICP-QMS as a tool to identify their source. Talanta 73(4):700-709

17. Catanzaro EJ et al (1968) Absolute isotopic abundance ratios of common, equal-atom, and radiogenic lead isotopic standards. J Res Natl Bur Stand Sect A Phys Chem 72(3):261 
18. Khumalo N, Mathuthu M (2018) Determination of trace elements and lanthanide (REE) signatures in uranium mine products in South Africa by means of inductively coupled plasma mass spectrometry. J Geochem Explor 186:235-242

19. Encinar JR et al (2001) A comparison between quadrupole, double focusing and multicollector ICP-MS instruments Part I Evaluation of total combined uncertainty for lead isotope ratio measurements. J Anal At Spectrom 16(4):315-321
Publisher's Note Springer Nature remains neutral with regard to jurisdictional claims in published maps and institutional affiliations. 